Bio - grafía. Escritos sobre la Biología y su Enseñanza. ISSN 2027-1034

Edición Extraordinaria. p.p. 1516 - 1519

Memorias del IX Encuentro Nacional de Experiencias en Enseñanza de la Biología y la Educación Ambiental. IV Congreso Nacional de Investigación en Enseñanza de la Biología.

\title{
ARTRÓPODOS PARA EDUCAR 2.0
}

\section{Víctor Manuel Marulanda Cruz ${ }^{1}$}

\section{RESUMEN:}

Artrópodos para educar 2.0 se origina con una reconstrucción de las actividades realizadas en la Línea de investigación Faunística y Conservación con Énfasis en los Artrópodos del Departamento de Biología de la Universidad Pedagógica Nacional a través de más de dos décadas, donde se ha pensado la enseñanza de la biología desde a interacción con organismos vivos en el aula, los artrópodos al ser uno de los grupos más diversos en el mundo posibilitan esta estrategia, además de que fortalecen actitudes tan importantes como la Biofilia.

En este taller se pretende socializar la construcción de diferentes kits educativos los cuales incluye organismos vivos como las mariposas, cucarachas y arañas, la forma de utilizarlos y crear espacios para fomentar experiencias educativa y la utilización de TICs, bajo reflexiones permanentes de índoles ambientales y sociales

PALABRAS CLAVE: Artrópodos, Kit educativo, Reflexiones ambientales, Enseñanza de la Biología, Biofilia

\section{ABSTRACT:}

Arthropods to educate 2.0 originates with a reconstruction of the activities carried out in the Line of research Faunística y Conservación con Énfasis en los Artrópodos of the Department of Biology of the National Pedagogical University through more than two decades, where it has been thought to teaching of Biology from interaction with living animals in the classroom, arthropods are the most the most diverse groups in the world make this strategy possible, in addition to strengthening attitudes as important as Biophilia.

This workshop intends to socialize the construction of different educational kits which include living organisms such as butterflies, cockroaches and spiders, the way of using them and the possible academic create spaces that Foster educational expieriences and the use of ICTs, under constant reflections of evironmental and social factors

KEYWORDS: Arthropods, Educational kit, Environmental reflections, Biology teaching, Biophilia

\footnotetext{
${ }^{1}$ Universidad Pedagógica Nacional. - Profesor en formación inicial - Departamento de Biología-.dbi_vmmarulandac160@pedagogica.edu.co. Voluntariado de la Línea Faunística y Cons ervación con Énfasis en los Artrópodos
} 
Bio - grafía. Escritos sobre la Biología y su Enseñanza. ISSN 2027-1034

Edición Extraordinaria. p.p. 1516 - 1519

Memorias del IX Encuentro Nacional de Experiencias en Enseñanza de la Biología y la Educación Ambiental. IV Congreso Nacional de Investigación en Enseñanza de la Biología.

\section{INTRODUCCIÓN Y PROPÓSTTOS:}

Qué mejor recurso para aprender de biología que interactuar con organismos vivos, este es el pilar fundamental para el desarrollo de este taller y el proceso investigativo y educativo que ha llevado La Línea de Faunística y Conservación con Énfasis en los Artrópodos durante más de dos décadas, Artrópodos para educar 2.0 retoma los diferentes ejercicios educativos que el profesor Rodrigo Torres y la Profesora Martha García han creado a lo largo de estos años, junto con diferentes estudiantes de la época, y los reestructura, integrando nuevas estrategias tecnologías para la enseñanza de la biología.

Colombia al igual que Brasil comparte el primer lugar en término de biodiversidad mundial, y se encuentra además en el Programa de Naciones Unidad para el Medio Ambiente como uno de los 17 países megadiversos que albergan el $70 \%$ de la diversidad mundial en solo $10 \%$ del territorio; según la Infraestructura mundial de información sobre biodiversidad (GBIF) Colombia cuenta con más de 54.000 especies registradas, siendo el primer país con mayor diversidad de aves y orquídeas, el segundo país con mayor diversidad de plantas, anfibios, peces de río y mariposas, el tercer país con mayor diversidad de reptiles y palmas y el cuarto país con mayor diversidad de mamíferos, contando además con 311 tipos de ecosistema a lo largo de su territorio continental y costero (IAvH, 2014).

Bogotá cuenta con una extensión de 163.660 .94 ha $(23.41 \%$ área urbana y $76,56 \%$ área rural), la cual posee una diversidad de ecosistemas que asciende a más de 90 tipos rurales y a más de 400 unidades ambientales urbanas, en donde habitan más de 600 especies de flora y potencialmente más de 200 especies de fauna (Secretaría Distrital de Ambiente y Conservación Internacional, 2010).

Este taller va más allá de demostrar las posibilidades de enseñanza con la utilización de artrópodos sino que además busca fortalecer la biofilia por parte de los asistentes; el especialista en evolución Edward O. Wilson desarrolló de manera profunda el término de Biofilia, la cual argumenta que durante los millones de años el Homo sapiens creó una necesidad emocional profunda y congénita de estar en contacto cercano con el reto de los seres vivos, Biofilia significa "amor a la vida" e indica que el contacto con la naturaleza es esencial para el desarrollo psicológico humano; según Wilson, el intercambio hombre-naturaleza repercute en la inteligencia, las emociones, la creatividad, el sentido estético, la expresión verbal y la curiosidad (Wilson, 1984).

Además, se pretende que los diferentes asistentes interactúen con los organismos fomentando su curiosidad por conocer más acerca de los artrópodos, la idea igualmente es que se demuestre las posibilidades que brindan los artrópodos para ser utilizados en diferentes temáticas de la educación y que depende de la creatividad del maestro.

\section{ASPECTOS PROCEDIMENT ALES:}

El taller inicia con un pequeño video el cual se mostrará un Time-lapse del ciclo de vida de la mariposa monarca (Danaus plexippus) desde la eclosión del huevo hasta el rompimiento de la crisálida y el surgimiento del adulto [2:30 minutos], seguido a esto se les preguntará a los asistentes ¿Cuáles son los sentimientos que surgieron a raíz de ver estas imágenes?, después de los comentarios de los asistentes, se dará paso a 
Bio - grafía. Escritos sobre la Biología y su Enseñanza. ISSN 2027-1034

Edición Extraordinaria. p.p. 1516 - 1519

Memorias del IX Encuentro Nacional de Experiencias en Enseñanza de la Biología y la Educación Ambiental. IV Congreso Nacional de Investigación en Enseñanza de la Biología.

la justificación e importancia del taller y se procederá a utilizar los kits educativos, estos tienen como objetivo que los asistentes interactúen con los organismos vivos y en algunos casos en seco.

Los kits educativos se relacionan con los organismos a utilizar, los cuales serán:

- Mariposas (Danaus plexippus, Leptophobia aripa, Euremasp)

- Grillos (Acheta domesticus)

- Cucarachas (Periplaneta americana, Gromphadorhina portentosa)

- Arañas (Pamphobeteus fortis)

Estos kits contienen los elementos necesarios para la realización del taller de acuerdo con la especie, incluyendo de manera específica el organismo vivo; la idea se centra en que estos posibiliten transportarse sin mayor precaución con instrucciones de su utilización en cada uno de ellos, además, se recomienda utilizar estereoscopios 0 lupas (que no contienen los kids) para una mejor observación de los procesos.

Además de esto, se busca integrar las nuevas tecnologías de la información y la comunicación, por lo cual se pretende utilizar diferentes aplicaciones de realidad virtual en el taller con la utilización de gafas cardboard y videos $360^{\circ}$

Todas las interacciones con los organismos serán guiadas a través de preguntas orientadoras que tradicionalmente se han utilizado en este taller como (Torres Núñez \& García Sarmiento, 2011):

¿Por qué debiéramos utilizar insectos en el aula?

¿Qué podemos enseñar y aprender con ellos?

¿Qué especies podríamos usar?

¿Dónde podríamos hacerlo?

Al finalizar, se realizara la reflexión de acuerdo a la pregunta inicial, dado que se busca reconocer si los asistentes generaron apropiación frente a la biofilia a partir de las expresiones orales que se generen.

\section{BIBLIOGRAFÍA:}

IAvH. (2014). Instituto de Investigación de Recursos Biológicos Alexander von Humboldt. Obtenido de La biodiversidad y los servicios ecosistémicos: http://www.humboldt.org.co/es/component/k2/item/161-la-biodiversidad-ylosserviciosecosistemicos?ttemid=269\&highlight=YToxOntpOjA7czoxMzoiYmlv ZGI2ZXJza WRhZCI7fQ== 
Bio - grafía. Escritos sobre la Biología y su Enseñanza. ISSN 2027-1034

Edición Extraordinaria. p.p. 1516 - 1519

Memorias del IX Encuentro Nacional de Experiencias en Enseñanza de la Biología y la Educación Ambiental. IV Congreso Nacional de Investigación en Enseñanza de la Biología.

Secretaría Distrital de Ambiente y Conservación Internacional. (2010). Política para la gestión de la conservación de la Biodiversidad en el Distrito Capital. Bogotá, Colombia: Panamericana.

Torres Núñez, R., \& García Sarmiento, M. (2011). TALLER MARIPOSAS PARA EDUCAR. Bio -grafía Escritos sobre la Biología y su Enseñanza, 512 - 514.

Wilson, E. (1984). Biofilia. Edward O. Wilson, Estados Unidos. 